\title{
Hypopituitarism with paranoid psychosis: a description of two cases
}

\author{
S. A. W. DISSANAYAKE AND D. M. LEIBERMAN \\ From Bexley Hospital, Dartford Heath, Bexley, Kent
}

The association of psychiatric disorder with endocrine disturbance is well recognized and has been extensively described in the literature, particularly in relation to thyroid disorder. Nearly 100 cases of myxoedema with psychosis have been described since the Clinical Society of London reported mental changes in myxoedema in 1888 (Logothetis, 1963), and it is fairly frequently seen in clinical practice. Less commonly reported is the occurrence of psychosis as a complication of other endocrine diseases-notably, Cushing's syndrome, Addison's disease, hyperthyroidism, and hypopituitarism.

Simmonds, in his original description of a case in 1914, made passing reference to the inertia characteristic of hypopituitarism. Sheehan and Summers (1949) gave an account of psychiatric symptoms in their survey of 143 such cases. Marked mental torpor was observed in 59 cases, with loss of drive and initiative, lack of interest in friends and relatives, and no desire to return home from hospital. Other psychiatric symptoms, excluding those observed when patients were approaching coma, were noticed in 22 cases. They stated that there were commonly delusions, but that mania was rare. Blau and Hinton (1960) described a patient with hypopituitarism who developed a psychosis with memory loss and disorientation after recovering from a coma.

\section{CASE HISTORIES}

CASE 1 Mr. W.H.S. died, aged 69 years, in 1966. In 1946 he had collapsed in the street and had been admitted to a general hospital for a time. Shortly afterwards he began to lose his body hair. In 1950 he began to complain of interference with his body by others, and expressed delusions of persecution. He maintained that two people were playing with his genitals after putting him to sleep, and believed he was being sprayed with disinfectant. He was admitted to Bexley Hospital, Kent, on certificate on 1 August 1950. After admission he continued to express pronounced delusions of a persecutory nature about the staff and other patients. Although it was noted at the time that his appearance suggested possible endocrine disorder, this was not pursued. He was treated as a case of 'paraphrenia' and eventually was transferred to a chronic ward. He was querulous, abusive, and uncooperative, and had bouts of aggression. He was uncommunicative, but was often noted to speak or gesticulate apparently in response to auditory hallucinations. After several years his general health began to deteriorate, the delusions were less systematized, hallucinatory responses diminished, and he became inert.

FAMILY AND PERSONAL HISTORY There was no family history of psychiatric disorder. He had been a skilled factory worker until his admission to hospital. He was married with no children. His premorbid personality showed no abnormal features.

PREVIOUS MEDICAL HISTORY In 1926 he had been involved in a lorry accident and sustained a fracture of the maxilla and hard palate, a part of which was removed at operation. After this he seems to have suffered a decline in general health, though he continued to work. The decline seems to have accelerated after his collapse in 1946. After his admission to Bexley Hospital he had numerous investigations for what appeared to be an intractable anaemia, both in Bexley and at a teaching hospital. No cause for his mild anaemia was found. He was diagnosed at various times as having anaemia, nephritis, and once as having cardiac failure. He was latterly transferred to an infirmary ward for yet another investigation of his anaemia, when his external appearance, with a pallor not commensurate with his degree of anaemia, smooth skin, wrinkled face, absence of body hair, and atrophic genitalia suggested the possibility of hypopituitarism; this was confirmed.

INVESTIGATIONS Haemoglobin was $9.6 \mathrm{~g} / 100 \mathrm{ml}$; MCHC $38 \%$. Glucose tolerance curve was flat, fasting $84 \mathrm{mg}$, maximum $104 \mathrm{mg} / 100 \mathrm{ml}$. Urinary steroids: 17-hydroxycorticoids $0.5 \mathrm{mg} / 24 \mathrm{hr}$. After metapyrone had been given for two days the levels were $11.1 \mathrm{mg} / 24 \mathrm{hr}$, $4.5 \mathrm{mg} / 24 \mathrm{hr}$. This indicated a lack of adequate response. After ACTH had been given for four days the levels were $6.6 \mathrm{mg} / 24 \mathrm{hr}, 14.7 \mathrm{mg} / 24 \mathrm{hr}, 23.2 \mathrm{mg} / 24 \mathrm{hr}, 28.2$ $\mathrm{mg} / 24 \mathrm{hr}$. This response was adequate.

Serum PBI was $0.5 \mu \mathrm{g} / 100 \mathrm{ml}$. Tri-iodo-thyronine resin uptake with ratio 0.87 . Serum cholesterol $241 \mathrm{mg} /$ $100 \mathrm{ml}$.

Radiograph of the skull showed no evidence of erosion of pituitary fossa, or of previous trauma.

Psychological tests gave a verbal I.Q. of 100, and 
Performance 85. There was no evidence of impaired memory or confusion.

TREATMENT AND PROGRESS After the diagnosis was established, the patient was started on replacement therapy with cortisone, thyroxine, and testosterone. There was a remarkable improvement in his general condition, as he gained $28 \mathrm{lb}$. in weight, and became active and more alert mentally. However, the delusional ideas persisted and efforts at rehabilitation were unsuccessful. A course of trifluoperazine failed to effect any improvement.

The patient died suddenly of cardiac infarction on 29 December 1966. Post-mortem examination revealed atrophy of the thyroid, testes, and adrenal cortex. The pituitary was a flattened disc $1 \mathrm{~cm} \times 0.8 \mathrm{~cm} \times 0.2 \mathrm{~cm}$. The macroscopic and microscopic changes were compatible with hypopituitarism of long duration. The appearance of the stump of the stalk suggested a possible traumatic causation.

CASE 2 Mr. N.E., aged 61 years, was first seen as a psychiatric patient in June 1966 at a domiciliary consultation. The patient presented in a bizarre manner with his head shaven, naked to the waist, and covered with ointment. He insisted that he was covered with crawling insects which were creeping over his body and biting him. In an attempt to convince the somewhat sceptical psychiatrist he vigorously scraped his head with a razor, washed the shavings in a saucer and demonstrated them as insects. He had at one time applied liquid insecticide to his face and scalp, producing a severe dermatitis, and had stayed locked indoors preoccupied in searching for the pests. He appeared to be auditorily hallucinated, hearing clicking noises made by the insects. He believed a queen parasite had entered his body, had multiplied rapidly, and that her removal would result in a cure. He gave the dimensions of the insects in fractions of an inch, their multiplicity of colours, and the rate of reproduction. He showed no evidence of intellectual impairment, memory loss or confusion. The illness was of recent onset, not more than of two months' duration. He was unwilling to enter hospital and was admitted later on an order when his condition at home appeared to be deteriorating.

FAMILY AND PERSONAL HISTORY There was no family history of psychiatric disorder. He left school at 16 and worked as a motor mechanic until the age of 49 when his endocrine disorder was first diagnosed. He ceased working owing to physical deterioration, and remained at home helping his mother and pursuing hobbies. He had never developed secondary sexual characteristics, had no libidinal drive, and no interest in the opposite sex. He had appeared happy at home and was known and liked in the neighbourhood.

PREVIOUS MEDICAL HISTORY From the age of 30 to the age of 49 he had attended various hospitals on account of abdominal pain; nothing pathological was found, and apparently his endocrine disorder was not noted. In 1956 he attended the Central Middlesex Hospital, where his characteristic appearance led to a diagnosis of hypoz pituitarism, and investigation revealed that he had af intrasellar craniopharyngioma. He was given replacement therapy with thyroxin, cortisone, and testosterone. Fron 1963 he was given only thyroxine, and his medication appears to have been irregular.

INVESTIGATIONS Haemoglobin was $12.8 \mathrm{~g} / 100 \mathrm{~m}$ MCHC $35 \%$, BMR $-29 \%$. A glucose tolerance curve was flat, fasting $70 \mathrm{mg}$, maximum $100 \mathrm{mg} / 100 \mathrm{mR}$. Urinary steroids: 17-hydroxycorticoids $10.7 \mathrm{mg} / 24 \mathrm{hr}$ After metapyrone for two days the levels were $8.4 \mathrm{mg}$ $24 \mathrm{hr}, 9.7 \mathrm{mg} / 24 \mathrm{hr}$. This showed a lack of responseo After ACTH had been administered for four days the were $11.7 \mathrm{mg} / 24 \mathrm{hr}, 31.2 \mathrm{mg}$. $/ 24 \mathrm{hr}, 34.6 \mathrm{mg} / 24 \mathrm{~h}$ h. $21.6 \mathrm{mg} / 24 \mathrm{hr}$. This showed an adequate response. The tri-iodo-thyronine resin uptake ratio was 0.44. Serun? cholesterol $390 \mathrm{mg} / 100 \mathrm{ml}$.

Radiology showed a marked enlargement of the pituitary fossa with erosion of the posterior clinoid processes, suggesting a pituitary tumour.

On perimetry there was no evidence of visual fiel defect.

TREATMENT AND PROGRESS He was treated as an inê patient in Bexley Hospital for three months and sub $\frac{N}{\omega}$ sequently on an out-patient basis by substitution theresp with cortisone, thyroxin, and methyltestosterone. Wherew his psychosis failed to respond, trifluoperazine was addedo He made slow but steady improvement punctuated watp a few minor relapses and now has a remission last several months. He has resumed his home life, looking after his aged mother.

\section{DISCUSSION}

The symptoms of hypopituitarism are due to the effect of lack of trophic hormones on the target organs, especially the adrenal cortex and the thyroid. The commonest cause is post-partum necrosis of theू anterior pituitary (Sheehan's syndrome). Less common are non-functioning tumours of the pituitary $\overrightarrow{0}$ and neighbouring structures, injuries to the base of the skull, infection, granulomata, and simple cysts?

The interesting features of the first case are the aetiology of the hypopituitarism and the duration of the syndrome. It seems most likely that the heado injury sustained in 1926 caused either direct damageto the pituitary or a secondary ischaemic necrosis re 3 . sulting in hypopituitarism lasting for $\mathbf{3 8}$ years witho psychosis for the 16 terminal years. It illustrates that occasional cases of psychosis of organic origin witho an unusual or uncommon aetiology may be overlooked. In the second patient the age of onset of theo pituitary disorder is uncertain, though it must have started before adolescence as secondary sexualos characteristics did not develop. The total duration of 0 his psychosis has been approximately two years, N though treatment was started within a relatively

(2)


short time after onset. After about one and a half years of treatment, the psychosis appears to have remitted.

The relation of endocrine disease to mental illness is a complex, unelucidated problem. Endocrine disorders causing either a deficiency or excess of some hormone may produce similar psychiatric syndromes. Disturbances of hormonal physiology have been postulated as contributory factors in the aetiology of mental illness, with the relative importance varying according to the writer. Changes of brain metabolism have been demonstrated in hypothyroidism (Scheinberg, Stead, Brannon, and Warren, 1950). The relative hypoxia, hypoglycaemia, adrenocortical and thyroid deficiencies, and associated complex metabolic and electrolyte changes must all have contributed a share in the aetiology of the psychosis in these cases. Both patients exhibited symptoms of psychosis after prolonged periods of hormonal deficiency. If, as seems reasonable, the psychosis was the result of this deficiency, and due to some change in the central nervous system, the long latent period is of interest. One can only speculate why the central nervous system seems so resistant to what are profound changes in the internal environment, and why, once the psychotic state has been induced and has persisted for a period of time, it is equally resistant to reversal.

In myxoedema, Asher (1949) noted that 'prolonged thyroid deficiency may well cause psychiatric changes which do not respond to thyroid'. In Tonk's (1964) group of 18 patients with hypothyroidism associated with mental illness, six patients recovered with specific treatment and 12 failed to do so. Those who recovered had their psychiatric symptoms for two years or less. The return to a state of physical health without any corresponding improvement in the mental condition of the first patient compared with the total improvement of the second, with substitution therapy and phenothiazines is, therefore, not unexpected.

\section{SUMMARY}

Two cases are described of hypopituitarism with paranoid psychosis without memory disturbance or mental confusion. In one patient the psychosis had lasted for 16 years and persisted, in spite of treatment with substitute hormones and phenothiazines which restored his physical health. There was a complete remission in the other patient with similar treatment whose symptoms had lasted for two years.

We wish to thank Dr. P. O'Gorman (pathologist, Woolwich Group of Hospitals), Dr. J. Staffurth (physician, Lewisham Hospital), and Dr. Mary McMillan (Lewisham Group Laboratory) for advice and pathological investigations, and also Professor P. M. Daniels (Institute of Psychiatry) and Dr. I. Williams (Department of Pathology, Brook General Hospital) for the postmortem examination of Mr. H.S. and histology.

\section{REFERENCES}

Asher, R. (1949). Myxoedematous madness. Brit. med. J., 2, 555-562. Blau, J. N., and Hinton, J. M. (1960). Hypopituitary coma and psychosis. Lancet, 1, 408-409.

Logothetis, J. (1963). Psychotic behaviour as the initial indicator of adult myxedema. J. nerv. ment. Dis., 136, 561-568.

Scheinberg, P., Stead, E. A., Jr., Brannon, E. S., and Warren, J. V. (1950). Correlative observations on cerebral metabolism and cardiac output in myxedema. J. clin. Invest., 29, 1139-1146.

Sheehan, H. I., and Summers, V. K. (1949). The syndrome of hypopituitarism. Quart. J. Med., 18, 319-378.

Tonks, C. M. (1964). Mental illnesses in hypothyroid patients. Brit. J. Psychiat., 110, 706-710. 